(с) А.Ю. Токмакова, Е.С. Грачева, Е.Л. Зайцева* , А.В. Воронцов

Национальный медицинский исследовательский центр эндокринологии, Москва

Диабетическая нейроостеоартропатия (остеоартропатия Шарко, ДНОАП, стопа Шарко) - это часто встречающееся осложнение диабетической нейропатии, которое в современной клинической практике относительно легко диагностируется и, при своевременном и адекватном лечении, корригируется, не приводя к выраженной деформации пораженного сустава. Представляем результат длительного клинического наблюдения за пациентом с ранним развитием осложнений сахарного диабета 2 типа, диабетической дерматопатией, распространенной ДНОАП с поражением суставов стоп, голеностопных, коленных и локтевых суставов. Особенностью описываемого клинического случая является распространенность костно-суставных нарушений с захватом нетипичных для диабета зон - коленных и локтевых суставов, поражение которых более характерно для других заболеваний (таких, как коллагенозы и сифилис), а также сочетание ДНОАП с диабетической дерматопатией. Представляется, что причины столь распространенного артропатического процесса лежат в длительном течении диабетической нейропатии, которая дебютировала задолго до постановки диагноза «сахарный диабет 2 типа», а также развитии и прогрессировании у данного пациента в последнее десятилетие наблюдения диабетической нефропатии и связанного с ней вторичного гиперпаратиреоза. В современной литературе описания сочетаний дерматопатий с другими осложнениями сахарного диабета крайне редки, а упоминания о комбинации распространенной ДНОАП и диабетического буллеза не встретились.

\title{
THE COMBINATION OF COMMON NEUROOSTEOARTHROPATHY AND DIABETIC DERMATOPATHY IN TYPE 2 DIABETES MELLITUS
}

\author{
(c) Alla Y. Tokmakova, Ekaterina S. Gracheva, Ekaterina L. Zaitseva*, Alexandr V. Vorontsov
}

Endocrinology Research Centre, Moscow, Russia

Diabetic neuroosteoarthropathy (Charcot's osteoarthropathy, DNAP, Charcot's foot) is a common complication of diabetic neuropathy, which can be easily diagnosed in clinical practice and usually is corrected without leading to severe deformation of the affected joint in case of timely and adequate treatment. We present the result of long-term clinical observation of a patient with early development of complications of type 2 diabetes mellitus, diabetic dermatopathy, common DNOAP with damage to the joints of the feet, ankles, knees and elbows. A feature of the described clinical case is the prevalence of osteoarticular disorders with seizure of atypical diabetes zones - knee and elbow joints, the defeat of which is more characteristic of other diseases (such as collagenoses and syphilis), as well as a combination of DNOAP with diabetic dermatopathy. It seems that the causes of such a common arthropathic process lie in the long course of diabetic neuropathy, which debuted long before the diagnosis of type 2 diabetes, as well as the development and progression of this patient in the last decade of observing diabetic nephropathy and associated secondary hyperparathyroidism. In the modern literature, descriptions of combinations of dermatopathies with other complications of diabetes mellitus are extremely rare, and references to a combination of common DNAP and diabetic bullosis have not been found.

KEYWORDS: diabetes mellitus; charcot neuro-osteoarthropathy; dermatopathy

Диабетическая нейроостеоартропатия (ДНОАП, артропатия Шарко, нейровоспалительная остеоартропатия) - относительно безболевая, прогрессирующая, деструктивная артропатия одного или нескольких суставов, сопровождающаяся неврологическим дефицитом [1]. Впервые связь между периферической нейропатией и повреждением голеностопного сустава была установлена в конце XIX в. неврологом J.-M. Charkot при наблюдении за пациентами с поздними стадиями сифилиса. Позже подобные деформации были описаны при лепре, травмах спинного мозга, алкоголизме, а в 1936 г. W.R. Jordan опубликовал клинический случай артропатии при сахарном диабете (СД). На сегодняшний день именно это эндокринологическое заболевание является наиболее частой причиной развития нейроостеоартропатии. 
Распространенность ДНОАП, по данным Федерального регистра больных сахарным диабетом 20132016 гг., составляет 17,9\% при сахарном диабете 1 типа (СД1) и 7,4\% - при сахарном диабете 2 типа (СД2), острая стадия ДНОАП диагностируется в 0,15-2,5\% случаев [2].

Наиболее часто патологический процесс локализуется в костях и суставах стоп, преимущественно предплюсне-плюсневых и суставах предплюсны. Крайне редко встречаются случаи ДНОАП с поражением коленного и даже локтевого суставов. В доступной литературе найдено описание 25 случаев поражения коленного сустава [3].

Представляем результат длительного клинического наблюдения за пациентом с ранним развитием осложнений СД2, диабетической дерматопатией, распространенной ДНОАП с поражением суставов стоп, голеностопных, коленных и локтевых суставов.

Диабетическая дерматопатия - распространенное, но недостаточно изученное осложнение СД. Согласно литературным данным, оно наблюдается у 30-50\% пациентов с СД [4]. На сегодняшний день описано около 30 видов заболеваний кожи, ассоциированных с нарушениями углеводного обмена. Отмечается, что дерматопатии могут как появляться на фоне уже манифестировавшего СД, так и являться его предикторами [5].

Диабетический буллез (диабетический пузырь, bullosis diabeticorum, diabetic bullae) - дерматоз, встречающийся у больных диабетом и характеризующийся высыпанием субэпидермальных пузырей, локализующихся чаще всего на передних поверхностях голеней [6]. В современной литературе описания сочетаний дерматопатий с другими осложнениями СД крайне редки, а упоминания о комбинации распространенной ДНОАП и диабетического буллеза нам не встретились.

\section{ОПИСАНИЕ СЛУЧАЯ}

Пациент Р., 75 лет, находился на стационарном лечении в отделении диабетической стопы «НМИЦ эндокринологии» с 11.09.2018 по 20.09.2019. Был госпитализирован с жалобами на жгучую боль в пальцах обеих стоп, возникающую в покое; судороги в мышцах голеней преимущественно в утренние часы; частое появление буллезных высыпаний на передней поверхности обеих голеней, скованность и боль в суставах нижних конечностей; снижение остроты зрения; полную утрату зрения на левом глазу.

Из анамнеза известно, что СД2 был диагностирован в 1993 г. (в возрасте 50 лет) на фоне снижения массы тела с 80 кг до 50 кг при росте 171 см без изменения режима питания и двигательной активности. Повышение гликемии (до 14 ммоль/л) впервые выявлено при госпитализации в инфекционное отделение ГКБ 31 по поводу эритематозных и буллезных высыпаний на передних поверхностях обеих голеней и предплечьях. Учитывая возраст пациента (50 лет) и отсутствие кетоза, диагностирован СД2. Обследования с целью дифференциальной диагностики типа СД не проводилось. Была назначена пероральная сахароснижающая терапия - глибенкламид (дозу не помнит). Спустя непродолжительный период времени вновь отметил появление папулезных высыпаний на коже голеней и кистей рук, по поводу которых обратился к дерматологу ЦНИКВИ им. Короленко, был диагностирован диабетический буллез. Пациент был госпитализирован в диабетологическое отделение Эндокринологического научного центра РАМН. В связи с декомпенсацией углеводного обмена была проведена коррекция сахароснижающей терапии: к принимаемому на тот момент гликлазиду добавлен инсулин средней продолжительности действия. Выполнялось местное лечение поверхностных раневых дефектов, сформировавшихся после вскрытия папул, с помощью жидких антисептиков и мазей на водорастворимой основе. В дальнейшем буллезные высыпания различной локализации (голени, предплечья, кисти рук) периодически возникали на всем протяжении болезни.

С 1994 г., в связи с неудовлетворительным гликемическим контролем, переведен на инсулинотерапию в режиме многократных инъекций препаратами человеческого инсулина, на фоне чего гликированный гемоглобин при ежегодной госпитализации в пределах 6-8,3\%. Групповое обучение самоконтролю заболевания по структурированной программе не проходил. Обучался индивидуально правилам учета углеводов, самостоятельной коррекции доз препаратов инсулина, профилактике и купированию гипогликемических состояний. В 2012 г. впервые переведен на аналоги человеческого инсулина - инсулин аспарт и детемир. Терапия на момент госпитализации: инсулин детемир 10 Ед утром и 6 Ед вечером, инсулин аспарт 6-8 Ед перед основными приемами пищи. Количественную оценку потребляемых углеводов не проводит. Самоконтроль гликемии 1-2 раза в день (натощак, на ночь). Гипогликемических состояний не отмечает.

С 1993 г. (год диагностики СД2) отмечены первые признаки поздних осложнений. На основании жалоб пациента на чувство онемения, похолодания стоп, боль, парестезии, а также оценки вибрационной чувствительности (по градуированному камертону 128 Гц) диагностирована дистальная диабетическая нейропатия. В том же году, после механической травмы, пациент отметил деформацию левой стопы, была диагностирована ДНОАП, проводилась консервативная терапия: ограничение двигательной активности (методика изготовления индивидуальных разгрузочных повязок еще не была внедрена в отечественную клиническую практику).

В 1995 г. после повторной травмы отмечена деформация правого коленного сустава, в связи с чем пациент консультирован травматологом городской больницы. Проводилась пункция сустава, данных о внутрисуставном введении препаратов нет. В 1998 г. был направлен в ЦИТО им. Приорова для решения вопроса о возможности протезирования, в котором пациенту было отказано. Постоянно носит бандаж на правый коленный сустав.

С 1996 г. впервые отметил отечность, гиперемию, деформацию левого локтевого сустава. При обследовании диагностирована ДНОАП.

В 2001 г. диагностирован перелом шейки правого бедра, с последующей иммобилизацией и проведением скелетного вытяжения. 
Ежегодно с 1993 г. по 2002 г. в связи с диабетической ретинопатией обоих глаз выполнялись сеансы лазерной коагуляции сетчатки. В 1999 г. после тотального гемофтальма слева проведена витрэктомия. С 2003 г. выявлена открытоугольная глаукома, проведено оперативное лечение. Атрофия зрительных нервов обоих глаз диагностирована в 2009 г. Артифакия OD в 2010 г., OU в 2012 г.

В 2000 г. впервые диагностирована диабетическая нефропатия. В 2001 г. креатинин - 149 мкмоль/л, скорость клубочковой фильтрации (СКФ) 46 мл/мин/1,73 м², альбуминурия 19 г/л. Длительное время принимал ингибиторы ангиотензинпревращающего фермента (иАПФ). В 2004 г. диагностирована мочекаменная болезнь (МКБ). С 2006 г. по 2016 г. уровень креатинина 107-135 ммоль/л (СКФ 46-66 мл/мин/1,73 м²). В 2016 г. диагностирована нефропатия сочетанного генеза (диабетическая нефропатия, МКБ). Хроническая болезнь почек (ХБП) СЗаА1.

В 2009 г. впервые выявлено повышение паратиреоидного гормона (ПТГ) - 110,5 пг/мл (35-70), снижение кальция в моче - 1,2 ммоль/сут (2,50-8,00). Уровень общего кальция - 2,28 ммоль/л $(2,15-2,55)$, кальция ионизированного - 1,1 $(1,03-1,29)$ ммоль/л. Был диагностирован вторичный гиперпаратиреоз на фоне дефицита витамина D, рекомендована терапия активными формами витамина D. Терапию не получал.

В 2010 г. ПТГ - 140 пг/мл (35-70), СКФ 58 мл/мин/1,73 м², кальций - 2 ммоль/л, кальций ионизированный - 0,97 ммоль/л, кальциурия 0,27 ммоль/л, 25-ОН витамин D - 4 нг/мл (15-80), B-cross laps - 0,96 нг/мл (0-0,3). По данным денситометрии от 18.11.10 г.: Т-критерий L2-L3 поясничного отдела позвоночника -2,9, Т-критерий в проксимальном отделе бедра total -2,8, Т-критерий в лучевой кости -3,1, что соответствует остеопорозу. Был инициирован прием альфакальцидола 1,5 мкг в сутки. Препарат принимался нерегулярно. По УЗИ щитовидной и паращитовидных желез за весь период наблюдения околощитовидные железы не визуализировались.

В связи с низкой приверженностью лечению в 2012 г. сохранялись высокие показатели ПТГ (150,6 пг/мл (35-70)).

В 2016 г.: кальций общий - 2,38 ммоль/л, кальций ионизированный - 1,13 ммоль/л, кальций в моче 1,23 ммоль/л. Денситометрия: остеопороз по Т-критерию -2,2 в L2-L3, -2,3 total бедро, -3,4 total кисть.

Оценивая динамику нейроостеоартропатии по данным рентгенографии на фоне проводимой разгрузки (бандажи на крупные суставы, от использования ортезов пациент отказался из-за страха падения), отмечено вялопрогрессирующее течение осложнения на всем протяжении болезни.

В 1996 г. в остеоартропатический процесс был вовлечен локтевой сустав слева (рис. 1).

С 2009 г. на рентгенограмме коленных суставов отмечался остеопороз, параоссальные обызвествления, справа - деформация суставных поверхностей, расплющивание мыщелков большеберцовой кости с выраженной перестройкой костной структуры, асимметрия формы и размеров коленных суставов (правосторонний артрозоартрит с грубой деформацией суставных поверхностей, диабетическая артропатия) (рис. 2).

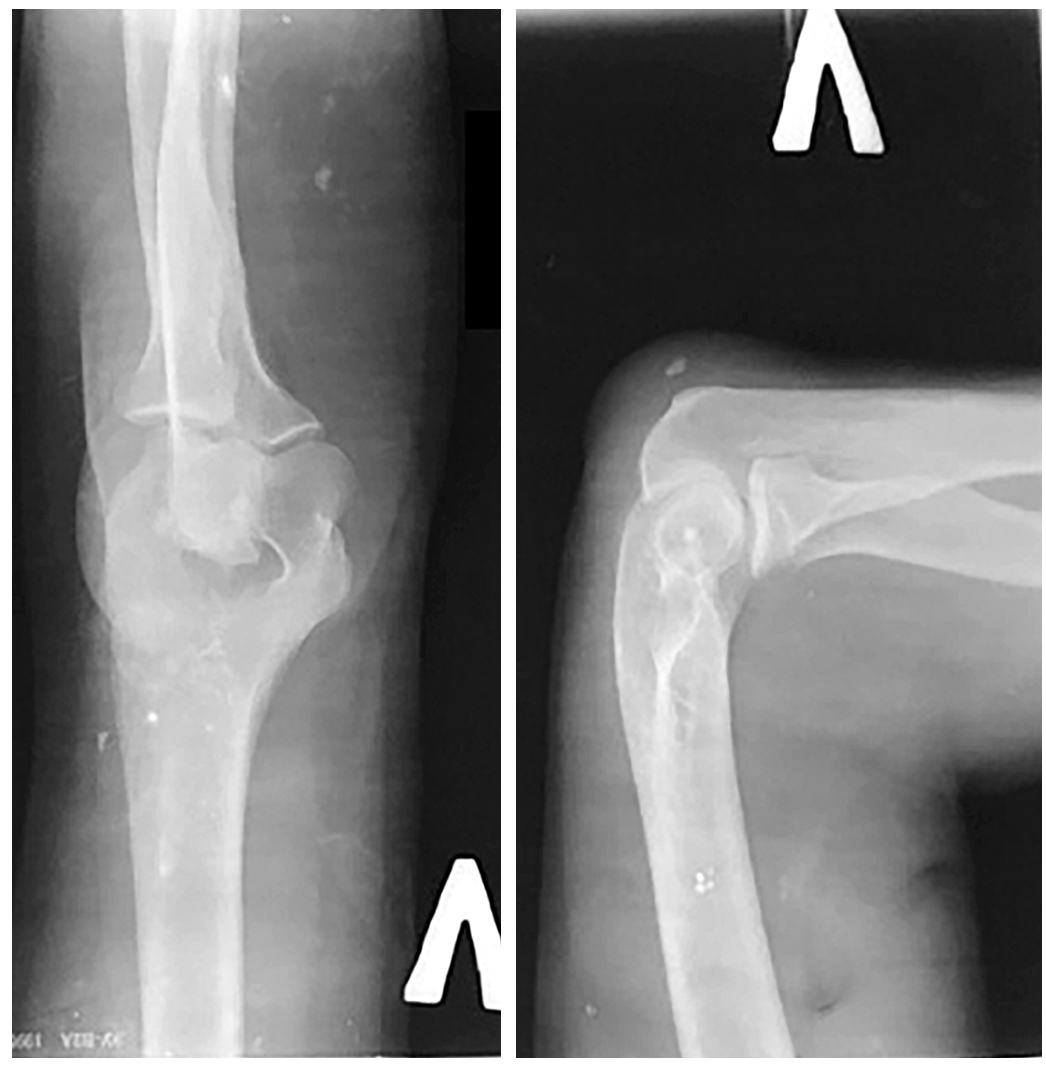

Рис. 1. Рентгенограммы левого коленного сустава, 1996 г.

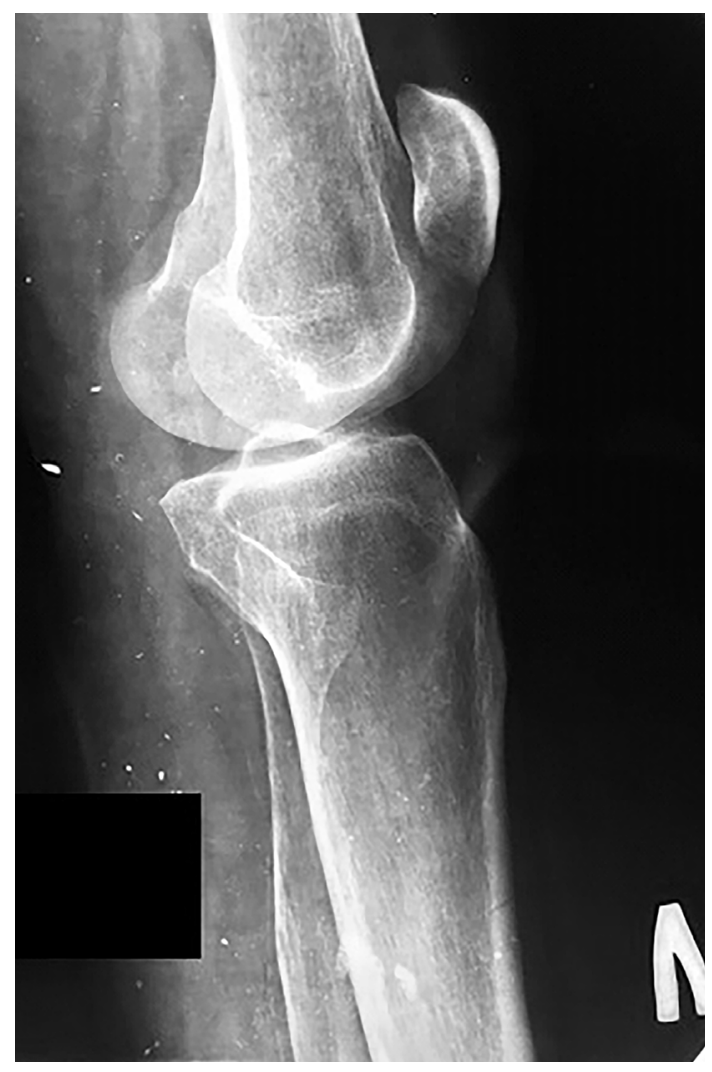

Рис. 2. Рентгенограмма левого коленного сустава, выполненная в боковой проекции, 2009 г. 

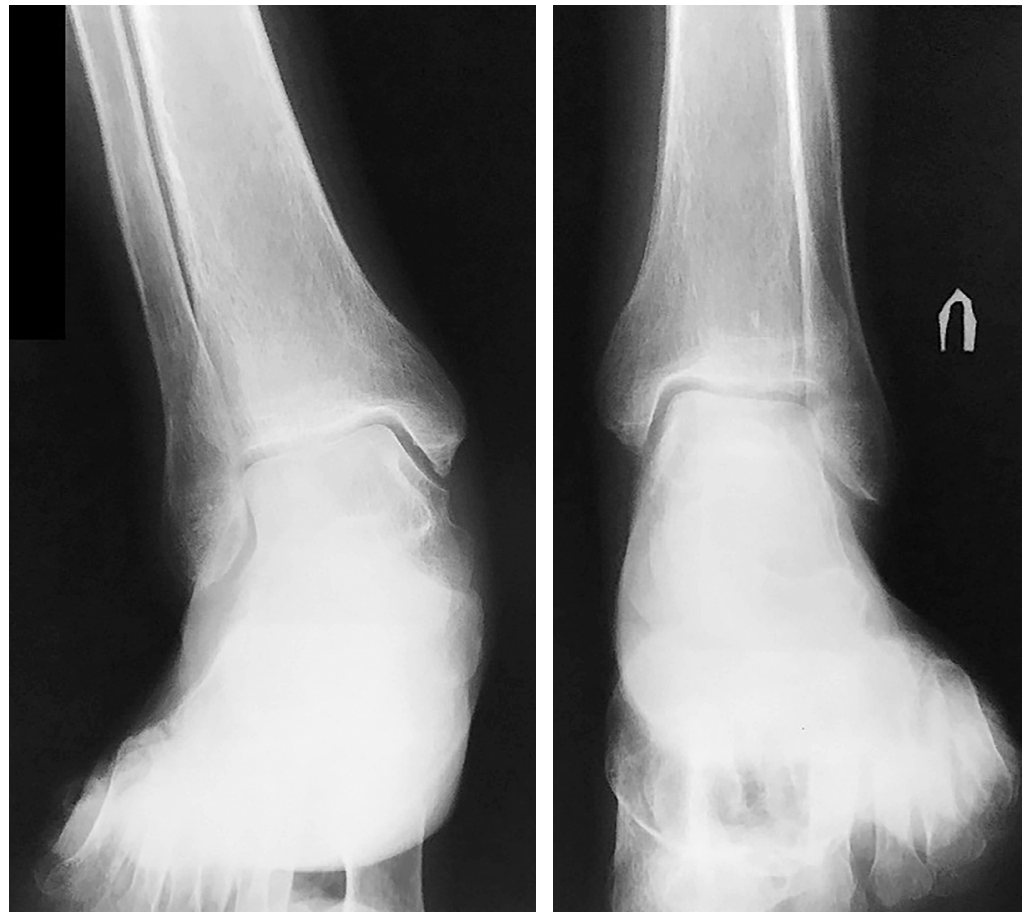

Рис. 3. Рентгенограммы голеностопных суставов, 2004 г.

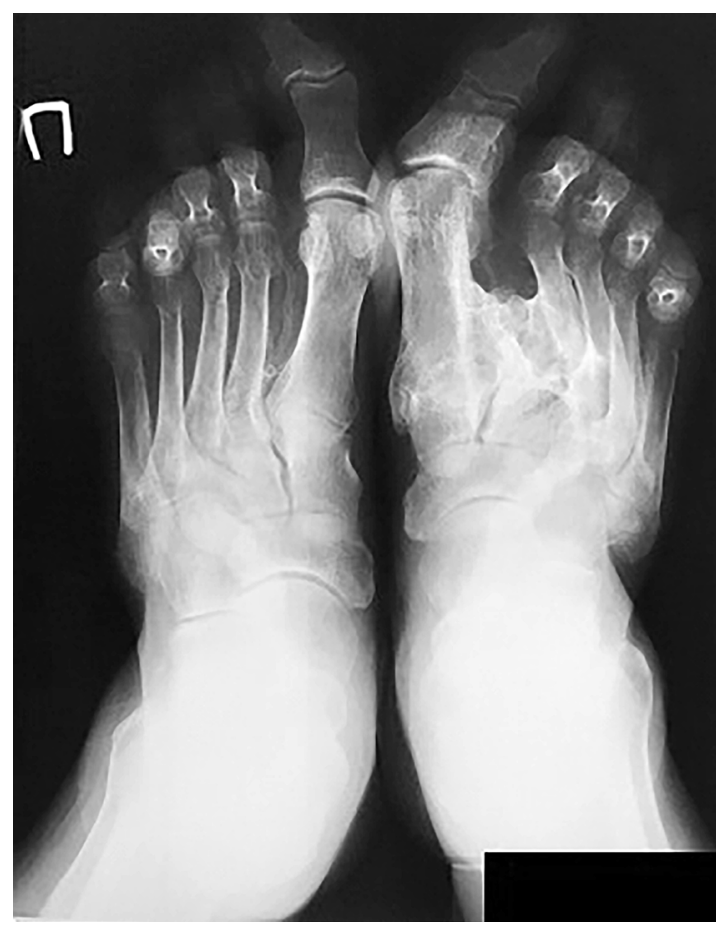

Рис. 4. Рентгенограмма обеих стоп, 2016 г.
С 2004 г. на рентгенограммах голеностопных суставов - выраженный грубый остеопороз, в области латеральных лодыжек - зоны Лоозера. Имеется дугообразная деформация плюсневых костей. Головка левой плюсневой кости утолщена, имеет остеопоретическиостеосклеротическую метаплазию костных балок с периостальными и параоссальными наслоениями. В мягких тканях IV стадия кальцификации (рис. 3).

Отмечено усиление остеолитических и остеопоротических процессов в фалангах пальцев, костях предплюсны, в крупных суставах - стабилизация процесса.

В 2016 г. зафиксирована грубая артропатическая перестройка структуры костей предплюсны и межплюсневых сочленений слева со вторичными подвывихами В них, грубый вторичный правосторонний артрозоартрит коленного сустава на фоне посттравматической чашеобразной деформации медиальных мыщелков правой бедренной и большеберцовой костей, подвывих справа (рис. 4).

Настоящая госпитализация - с целью обследования и возможной коррекции терапии.

Результаты физикального, лабораторного

и инструментального исследования

Локальный статус при поступлении: кожа стоп и голеней сухая, теплая на ощупь, отмечаются гиперпигментация, очаги вскрывшихся булл на голени. Внешний вид конечностей представлен на рис. 5. Стопы и правый коленный сустав деформированы (рис. 6).

При инфракрасной термометрии кожи конечностей выявлен температурный градиент на симметричных участках конечностей: на правой стопе $+3^{\circ} \mathrm{C}$, на правом коленном суставе $+2^{\circ} \mathrm{C}$ справа. Тактильная чувствительность снижена, температурная отсутствует, вибрационная (по градуированному камертону 128 Гц) 3-4 у.е. с обеих сторон в области бугров большеберцовых костей, ниже отсутствует.
За время госпитализации проведено комплексное обследование, по данным которого отмечена стабилизация осложнений СД. Гликированный гемоглобин 8,7\%. Проведено суточное мониторирование уровня гликемии: с учетом полученных данных скорректирована доза аналогов инсулина ультракороткого действия. На фоне терапии активными препаратами витамина D ПТГ 47,88 пг/мл (15-65), однако по результатам денситометрии положительной динамики не выявлено: минеральная плотность костной ткани по Т-критерию в L2 поясничного отдела позвоночника до -2,7, в шейке бедренной кости -2,6, в лучевой кости -3,8, что соответствует остеопорозу.

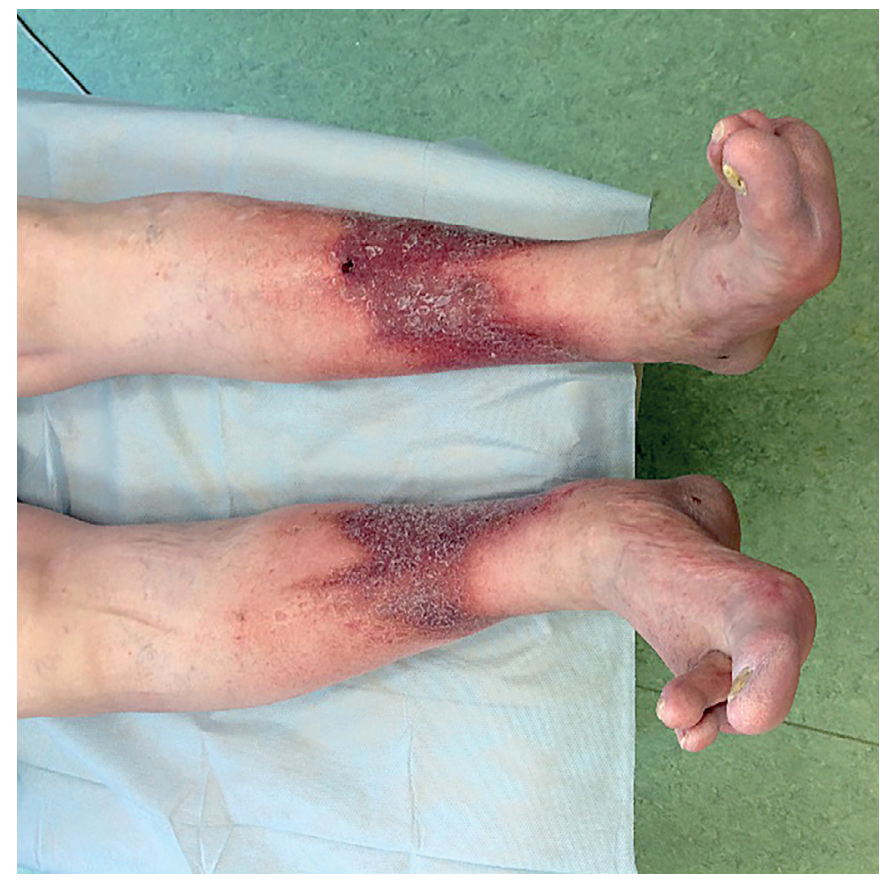

Рис. 5. Внешний вид конечностей при поступлении. Очаги вскрывшихся булл в области средней трети передней поверхности голеней 

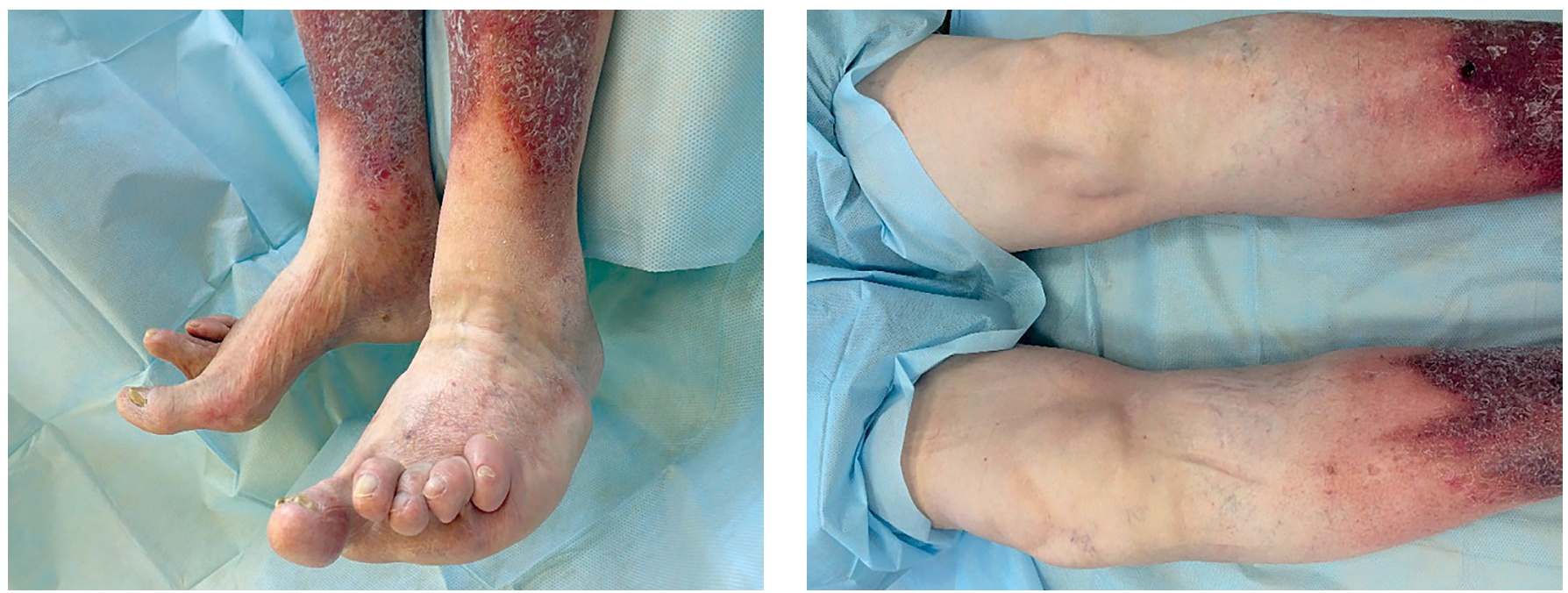

Рис. 6. Внешний вид деформации стоп и коленных суставов.

Проведенная эзофагогастродуоденоскопия подтвердила наличие гастроинтестинальной автономной нейропатии, что затрудняет достижение индивидуальных целевых показателей углеводного обмена.

По результатам МРТ нижних конечностей отмечается картина подострой стадии диабетической остеоартропатии (субхондральная кистозная перестройка, отек пяточной кости, отек и инфильтрация мягких тканей стопы, воспалительные изменения голеностопного сустава).

На рентгенограмме (рис. 7) отмечены признаки диффузного остеопороза, наличие участков фиброзно-кистозной перестройки в дистальных эпиметафизах большеберцовой и малоберцовой кости, таранных костях. Левая стопа деформирована за счет консолидации со смещением отломков оснований 1-4-й плюсневых костей с массивными периоссальными наслоениями и нарушением конфигурации в суставе Лисфранка. Отмечаются подвывихи в межфаланговых суставах 2-го, 4-го, 5-го пальцев, молоткообразная деформация плюсневых и фаланговых косточек, деформирующий артроз в плюснефаланговых и межфаланговых суставах; признаки диффузного остеопороза, фиброзно-кистозной перестройки эпиметафизов фаланг и костей плюсны и предплюсны. На рентгенограмме правой стопы в прямой проекции отмечается варусная деформация, hallux valgus 1-го пальца с подвывихом в межфаланговом суставе, пальцы стопы клювовидно искривлены в подошвенную сторону, с акцентом на 4-й палец, межплюсневые промежутки расширены. Фаланги пальцев и плюсневые кости молоткообразно деформированы, с фиброзно-кистозной
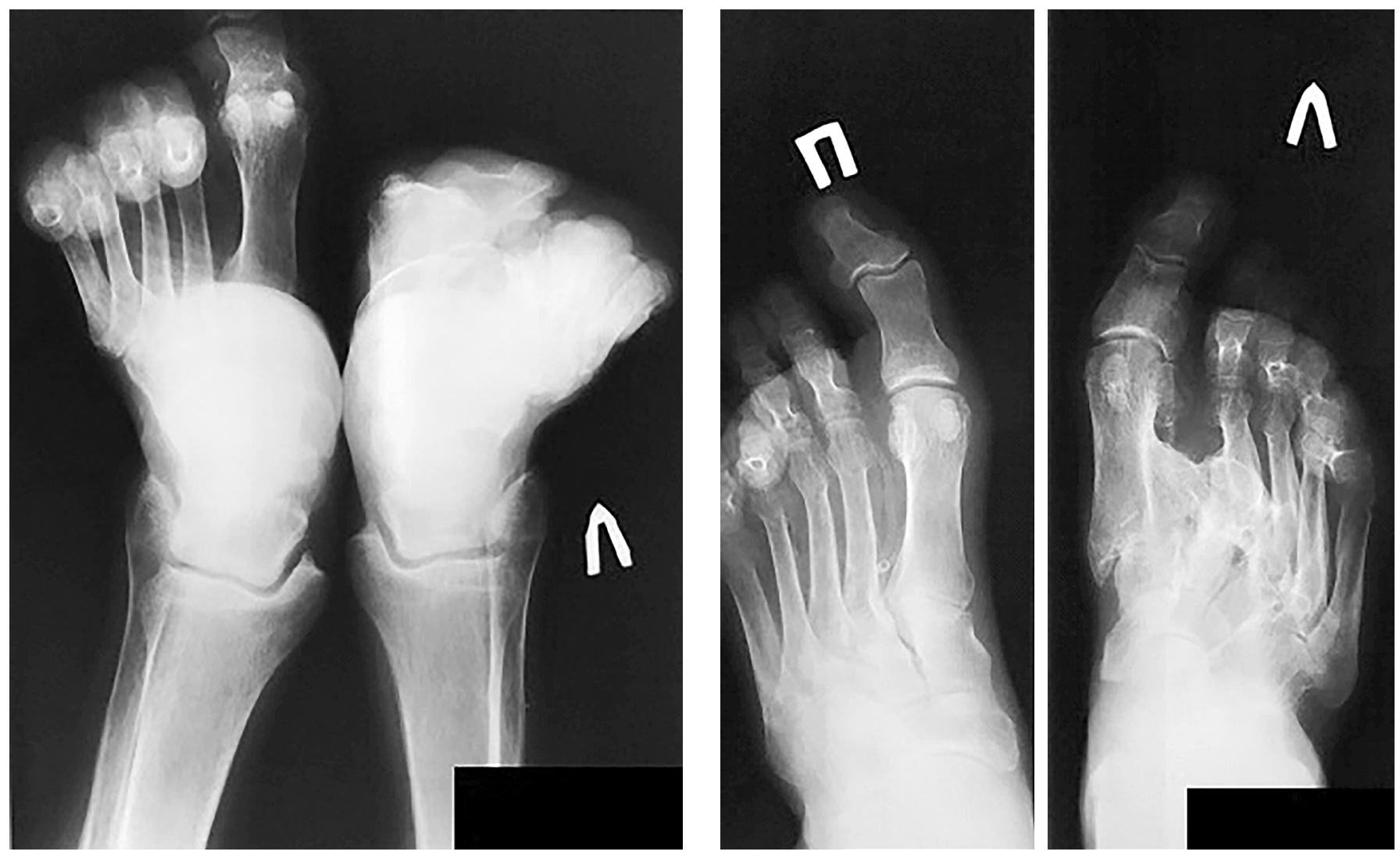

Рис. 7. Рентгенограмма обеих стоп при поступлении, 2018 г. 

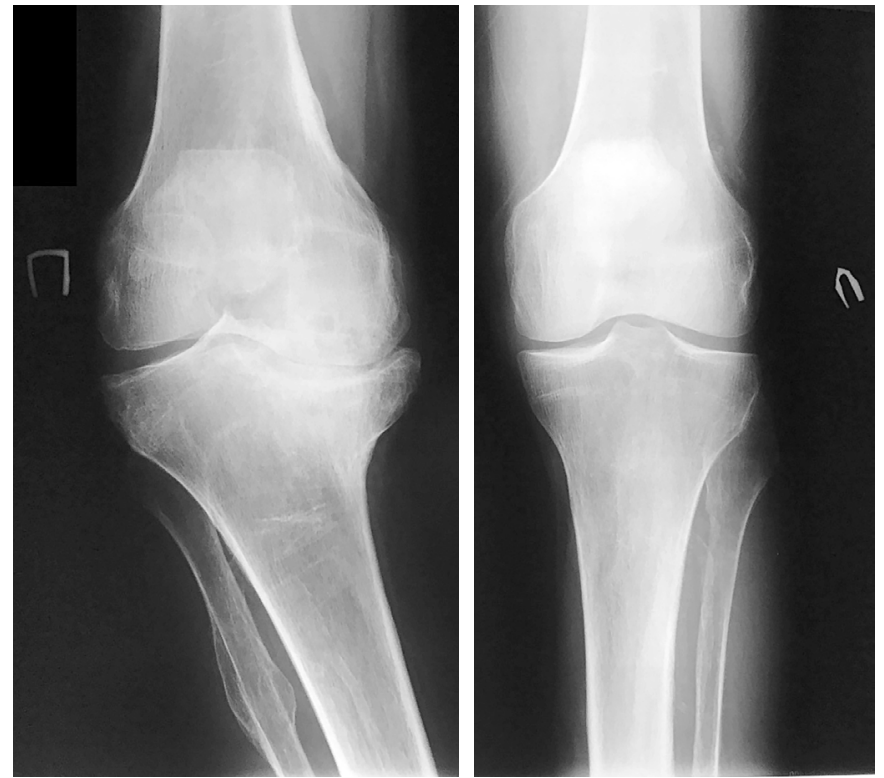

Рис. 8. Рентгенограмма обоих коленных суставов при поступлении, 2018 г.

перестройкой эпиметафизов. На рентгенограмме левого и правого коленного сустава - остеопороз, остеоартроз справа с посттравматической деформацией медиального мыщелка правой большеберцовой кости с перестройкой межмыщелкового ареолярного поля и девиацией межмыщелковых возвышений правой большеберцовой кости кнаружи. Консолидированный перелом диафиза правой малоберцовой кости.

На рентгенограммах коленных суставов (рис. 8) травматический подвывих справа бедренной кости, большеберцовой с признаками двигательной нестабильности в суставе, хронический бурсит задне/наружного квадранта. Слева - средневыраженный артроз с ротационным подвывихом.

На рентгенограммах локтевых суставов (рис. 9) - картина хронической стадии ДНОАП с обеих сторон.

Таким образом, был сформулировал клинический диагноз.

Основное заболевание: Сахарный диабет 2 типа.

Осложнения основного заболевания: Диабетические микроангиопатии: Пролиферативная ретинопатия обоих глаз. Состояние после лазерной коагуляции сетчатки обоих глаз (1993-2002 гг.). Оба глаза - артифакия. Левый глаз - авитрия, атрофия зрительного нерва. Оба глаза - оперированная лазером IV глаукома. Нефропатия сочетанного генеза (диабетическая, МКБ). ХБП СЗбА 1.

Дистальная диабетическая полинейропатия. Диабетическая остеоартропатия, подострая стадия с поражением суставов стоп, голеностопных, хроническая стадия в коленных, локтевых суставах. Диабетическая автономная нейропатия, гастроинтестинальная форма, диабетическая энтеропатия. Диабетическая кардиомиопатия.

Сопутствующие заболевания: Гипертоническая болезнь II стадии, степень 2, риск 4. Вторичный остеопороз. Мочекаменная болезнь. Коралловидные конкременты обеих почек. Аксиальная грыжа пищеводного отверстия диафрагмы. Гастроэзофагеальная рефлюксная болезнь. Атрофический гастрит. Хронический панкреа-
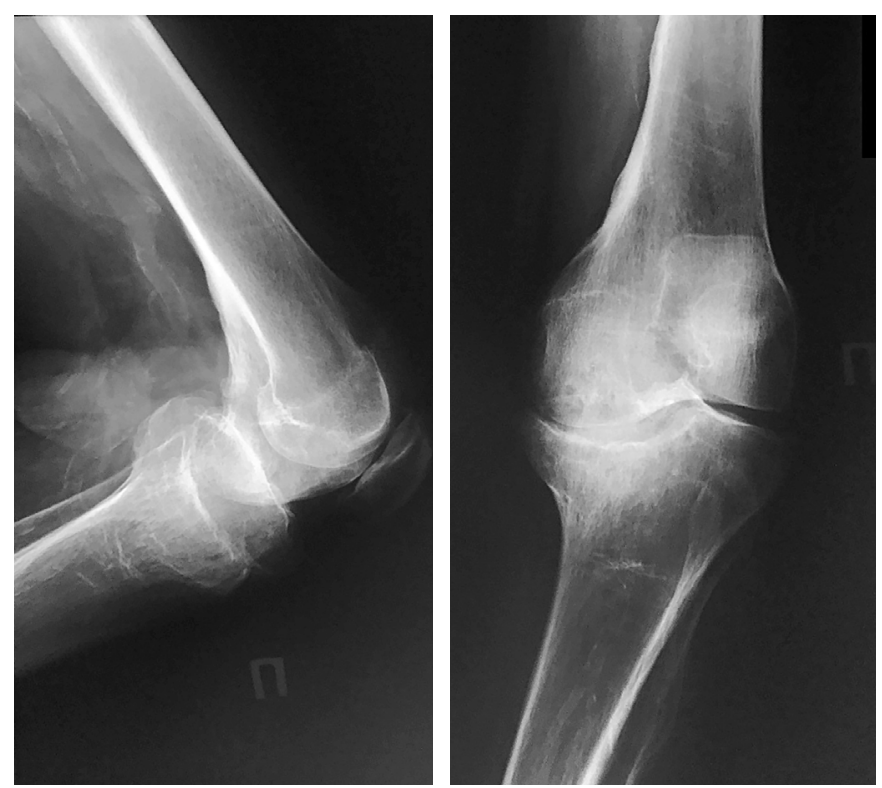

Рис. 9. Рентгенограммы локтевых суставов при поступлении, 2018 r.

тит в стадии ремиссии. Хронический двусторонний пиелонефрит, латентное течение. Кисты обеих почек. Аденома простаты. Хронический конгестивно-инфекционный простатит, стадия обострения.

Проведено лечение: Инсулин Детемир: 10 Ед в 8.00, 6 Ед в 22.00 в подкожножировую клетчатку живота постоянно; инсулин Аспарт при гликемии до 10 ммоль/л 8 Ед, при гликемии больше 10 ммоль/л - 10 Ед за 10 мин до основных приемов пищи. Антигипертензивная терапия: Фуросемид 20 мг утром постоянно. Периндоприл 2,5 мг вечером постоянно. Антилипидемические препараты: Аторвастатин 20 мг вечером постоянно. Антиагрегантная терапия: Ацетилсалициловая кислота в кишечнорастворимой оболочке 75 мг + магния гидроксид 12,5 мг вечером после еды постоянно. Гастропротективная терапия: Омепразол 20 мг утром постоянно. Ферментные препараты: Панкреатин в кишечнорастворимой форме 25000 ЕД по 1 капсуле в основные приемы пищи, постоянно. Терапия остеопороза: Альфакальцидол 1 мкг утром. Гипоурикемическая терапия: Аллопуринол 100 мг утром постоянно. Терапия антиконвульсантами: Прегабалин по 150 мг утром и вечером.

\section{ОБСУЖДЕНИЕ}

СД2 - поздно диагностируемое заболевание, что часто влечет за собой длительный период бессимптомной гипергликемии, следствием которого является достаточно быстрое развитие осложнений. По данным современной литературы, признаки нейропатии обнаруживаются у 11,3\% лиц с нарушенной гликемией натощак и у $13 \%$ с нарушенной толерантностью к глюкозе [7]. В данном наблюдении мы хотели показать стремительное формирование и прогрессирование практически всех микрососудистых осложнений у пациента с СД2 с удовлетворительным контролем углеводного обмена практически на протяжении всего периода. Особенностью данного случая является сочетание распространенного остеоартропатического процесса и рецидивирующего диабетического буллеза. 
ДНОАП (остеоартропатия Шарко, стопа Шарко) достаточно часто встречающееся осложнение диабетической нейропатии, которое в современной клинической практике относительно легко диагностируется и, при своевременном и адекватном лечении, корригируется, не приводя к выраженной деформации пораженного сустава. Особенностью описываемого клинического случая является распространенность костно-суставных нарушений с захватом нетипичных для диабета зон коленных и локтевых суставов, поражение которых более характерно для коллагенозов и сифилиса. Представляется, что причины столь распространенного артропатического процесса лежат в длительном течении диабетической нейропатии, дебютировавшей еще задолго до диагностики СД2, а также развитии и прогрессировании в последнее десятилетие наблюдения диабетической нефропатии и связанного с ней вторичного гиперпаратиреоза.

\section{ЗАКЛЮЧЕНИЕ}

Приведенный клинический случай является примером развития различных редких осложнений СД на фоне практически удовлетворительного контроля заболевания. Крайне редко выявляемая распространенная ДНОАП требует тщательного и внимательного осмотра и анализа анамнестических данных, а проведение дифференциальной диагностики других заболеваний костно-суставного аппарата с ДНОАП позволит снизить риски деформаций и формирования ран нижних конечностей.
Трудность в курации пациента определялась проблемами в достижении целевых показателей гликемии, обусловленными множественными выраженными микрососудистыми осложнениями диабета, приведшими к резкому снижению возможностей больного к самоконтролю углеводного обмена (практически полная потеря зрения), нарушению всасывания углеводов в желудочно-кишечном тракте вследствие автономной гастроинтестинальной нейропатии, а также крайне высокому риску падений, что ограничивает использование средств иммобилизации пораженных суставов.

\section{ДОПОЛНИТЕЛЬНАЯ ИНФОРМАЦИЯ}

Источник финансирования. Публикация настоящей работы выполнена при финансовой поддержке научно-исследовательской работы в рамках государственного задания № АААА-А18-118051590055-8 «Метаболические и генетические маркеры репарации мягких тканей и костных структур нижних конечностей у больных сахарным диабетом, их роль в прогнозировании, персонифицированной терапии и профилактике синдрома диабетической стопы».

Согласие пациента. Пациент добровольно подписал информированное согласие на публикацию персональной медицинской информации в обезличенной форме в журнале «Сахарный диабет».

Конфликт интересов. Авторы декларируют отсутствие явных и потенциальных конфликтов интересов, связанных с публикацией настоящей статьи.

Благодарности. Авторы выражают благодарность сотрудникам отделения диабетической стопы и отдела лучевой диагностики за помощь в подготовке данного клинического случая.

\section{СПИСОК ЛИТЕРАТУРЫ | REFERENCES}

1. Дедов ИИ, Шестакова МВ, Майоров АЮ, и др. Алгоритмы специализированной медицинской помощи больным сахарным диабетом / Под ред. И.И. Дедова, М.В. Шестаковой, А.Ю. Майорова. 9-й вып. // Сахарный диабет. - 2019. - Т. 22. №S1. - C. 1-144. [Dedov II, Shestakova MV, Mayorov AYu, et al. Standards of specialized diabetes care. Ed. by Dedov II, Shestakova MV, Mayorov AYu. 9th edition. Diabetes mellitus. 2019;22(S1):1-144. (In Russ.)] doi: https://doi.org/10/14341/DM221S1

2. Галстян Г.Р., Викулова, О.К., Исаков М.А., и др. Эпидемиология синдрома диабетической стопы и ампутации нижних конечностей в Российской Федерации по данным Федерального регистра Больных сахарным диабетом 2013-2016 гг. // Сахарный duaбem. - 2018. - T. 21. — №3. - C. 170-177. [Galstyan GR, Vikulova OK, Isakov MA, et al. Trends in the epidemiology of diabetic foot and lower limb amputations in Russian Federation according to the Federal Diabetes Register (2013-2016). Diabetes mellitus. 2018;21(3):170-177. (In Russ.)] doi: https://doi.org/10.14341/DM9686

3. Галстян Г.Р., Каминарская Ю.А. Патогенез остеоартропатии Шарко: роль периферической нервной системы //
Эндокринная хирургия. - 2014. - Т. 8. - №4. - С. 5-8. [Galstyan GR, Kaminarskaya YuA. The pathogenesis of Charcot osteoarthropathy: the role of the peripheral nervous system. Endokrinnaia khirurgiia. 2014;8(4):5-8. (In Russ.)] doi: https://doi.org/10.14341/serg201445-14

4. Goyal A, Raina S, Kaushal SS, et al. Pattern of cutaneous manifestations in diabetes mellitus. Indian J Dermatol. 2010;55(1):39-41. doi: https://doi.org/10.4103/0019-5154.60349

5. Katsambas AD, Lotti TM, Dessinioti C, D'Erme AM. European handbook of dermatological treatments. 3rd ed. Springer-Verlag Berlin Heidelberg; 2015. 1579 p. doi: https://doi.org/10.1007/978-3-662-45139-7

6. Romano G, Moretti G, Di Benedetto A, et al. Skin lesions in diabetes mellitus: prevalence and clinical correlations. Diabetes Res Clin Pract. 1998;39(2):101-106 doi: https://doi.org/10.1016/s0168-8227(97)00119-8

7. Sumner CJ, Sheth S, Griffin JW, et al. The spectrum of neuropathy in diabetes and impaired glucose tolerance. Neurology. 2003;60(1):108-111. doi: https://doi.org/10.1212/wnl.60.1.108

\section{ИНФОРМАЦИЯ ОБ АВТОРАХ [AUTHORS INFO]}

*Зайцева Екатерина Леонидовна, к.м.н. [Ekaterina L. Zaitseva, MD, PhD]; адрес: Россия, 117036, Москва, ул. Дм. Ульянова, д. 11 [address: 11, Dm. Ulyanova street, 117036 Moscow, Russian Federation]; ORCID: https://orcid.org/0000-0002-3735-019X; eLibrary SPIN: 1075-3022; e-mail: zai.kate@gmail.com

Грачева Екатерина Сергеевна, клинический ординатор [Ekaterina S. Gracheva, MD, clinical resident]; ORCID: https://orcid.org/0000-0002-8930-8399; eLibrary SPIN: 8339-4239; e-mail: gra4ik@mail.ru

Токмакова Алла Юрьевна, д.м.Н., гл.н.с. [Alla Y. Tokmakova, MD, PhD, chief research associate]; ORCID: https://orcid.org/0000-0003-2474-9924; eLibrary SPIN: 7479-7043; e-mail: alla-tokmakova@yandex.ru

Воронцов Александр Валерьевич, д.м.н. [Aleksandr V. Vorontsov, MD, PhD];

ORCID: https://orcid.org/0000-0002-2791-3278; eLibrary SPIN: 2502-4463; e-mail: mr2005i@mail.ru 


\section{ЦИТИРОВАТЬ:}

Токмакова А.Ю., Грачева Е.С., Зайцева Е.Л., Воронцов А.В. Сочетание распространенной нейроостеоартропатии и диабетической дерматопатии при сахарном диабете 2 типа // Сахарный диабет. — 2020. — Т. 23. — №2. — С. $201-208$. doi: https://doi.org/10.14341/DM12069

\section{TO CITE THIS ARTICLE:}

Tokmakova AY, Gracheva ES, Zaitseva EL, Vorontsov AV. The combination of common neuroosteoarthropathy and diabetic dermatopathy in type 2 diabetes mellitus. Diabetes Mellitus. 2020;23(2):201-208. doi: https://doi.org/10.14341/DM12069 